\title{
Influence of Adult Children's Family Size, Family Life Cycle and Income on Care of Elderly Parents in Nigeria
}

\author{
Emem Omokaro ${ }^{1}$ \\ National Universities Commission \\ Abuja
}

DOI: $10.36108 / \mathrm{NJSA} / 4102 / 12(0140)$

\author{
Ottong Joseph \\ Department of Sociology \\ University of Calabar \\ Calabar
}

${ }^{1}$ Corresponding Author: firstdavem@yahoo.com

\begin{abstract}
The study examined the influence of adult children's family size, stage in family life cycle and income on the provision of care to elderly parents among adult children working in University of Calabar, Nigeria. The cross-sectional study adopted a purposive sampling technique to select 350 consenting respondents. Family size was operationalized as the total number of children in the household consisting of the number of children still living in the house and those who are outside but still dependent on the respondent for some form of support. Stage in family life cycle was operationalized as the distribution of children in each education level (nursery, primary, secondary and higher institution) according to age range of adult children. Adult children income was measured as income of the respondents. Data were analysed using descriptive statistics and chi square test of significance. Findings revealed a significant relationship between adult children's family size and provision of care to the elderly. The more the number of children in the household within the indicated age ranges of adult children, the less the amount of care given to the elderly. Although income of adult children was not a significant predictor of provision of care given to elderly parents, the measured financial responsibility of adult children in respect of the number of children in the household still dependent on them for some form of support, indicated by the number of children in various levels of schooling, inversely affected adult children's care of elderly parents.
\end{abstract}

Keyword: elderly, family size, family life cycle, income, Calabar

\section{Introduction}

Population ageing globally is a rising development concern, and it is becoming crucial for sustainable development to address ageing and issues of older persons as it has implication for rise in health cost because of the different health conditions associated with aging (González et al., 2011) amongst other things. The number of older persons aged 60 and over in Africa is projected to increase from the 2007 figure of 50.5 million to 64.5 million in 2015, and reach 205 million by 2050 . This projection represents a population increase at an annual rate 3.3 per cent between 2015 and 2050 (UNDESA, 2007). Nigeria, the 
most populous country in Africa currently has the highest number of elderly population with an estimated figure of 8.8 million which accounts for 5.3 per cent of an estimated total population in 2012 (UNFPA/Help Age International, 2012).

The traditional notion still prevails that the extended family, with its structures and patterns of group solidarity and blood ties, would render virtually insignificant any problem associated with ageing. The general belief is that the family is a support system and that kinship ties to family members, especially children, guarantee assistance (Apt, 1993). This assumption of caregiving as an exclusively culturally oriented, systematic and learned behaviour has been posited by traditional development theories of Sociology: [i] Structural Functional perspective, which argues that caregiving behaviour by adult children is systematically learned and developed through socialization and internalization of cultural norms, [ii] The Role Theory perspective, which argues that caregiving is a normative requirement and social role prescription; and [iii] Exchange Theory perspective, which posits that care of the elderly by adult children is based on the norms of reciprocity and filial obligation. All the paradigms postulate that the adult children owe society and their parents, provision of services and the social values and the norms of society confer legitimacy on the moral rights of elderly parents to such services. By these assumptions, these classical theories cannot adequately explain social change and the influence of non-cultural variables on care of the elderly.

Although childhood socialization is crucial as normative determinant of caregiving behaviour and most adult children have internalized the cultural norms of reciprocity, and are obligated to take responsibility of caring for their elderly parent, adult children caregivers are often raising families of their own and pursuing careers while at the same time are helping elderly parents. Demographic, economic and social trend suggests that adult children may be facing a declining capacity to provide the kind of care the elderly parents' needs (Rosenmayr, 1993).

In the current debate on the care of elderly in Nigeria, and the traditional and moral persuasion of family to undertake obligatory responsibilities, relatively nothing has been discussed about adult children's situational exigencies which determine their responsiveness and capacity to provide services needed by elderly parents. The quality, capacity and responsiveness of adult children to provide care therefore cannot be divorced from the multichallenges faced by adult children that could determine caregiving behaviour. This study is aimed at investigating the factors of adult children's family size, stage in family life cycle and income as non-cultural variables influencing caregiving behaviour of adult children. Care of elderly as used in this study is defined as the unpaid services that adult children provide to adult parents which is of importance to the continued survival of the elderly parents. 


\section{Theoretical Framework}

The theoretical framework adopted for the purpose of this study is Symbolic Interaction and Phenomenology perspectives, the proposition that adult children care of the elderly parents is an Act of Decision making. The benefits of the shift in paradigm from care of the elderly as normative action and developmental behaviour learnt through socialization to caregiving as an Act of Decision making based on symbolic interaction and Phenomenology perspective allows the development of an expanded hypothesized relationship between family size, stage in family life cycle and income of the adult children and provision of services to elderly parents. The willingness, responsiveness and the capacity of adult children to provide care is explained within the context of their situational exigencies and the variables which influence their situated judgment. This framework recognizes the flexibility and adjustability within the normative operations which helps to overcome the theoretical tendency to categorize self-interest and situational conditions as divorced from and even antithetical to values and norms (Lidz, 1972).

The results of various studies of adult children's help to parents tend to be different or inconsistence and many times such differences are related to background variables. Cicirelli (1981), Shanas (1979), Townsend (1968), Horowits (1985) and Stone et al. (1997) also corroborate the above opinion that the socioeconomic status of the family appears to be an important factor in determining adult children care to elderly parents. Pearlin et al. (1990) further suggested that socio-economic characteristics of caregiving are likely to specify the care giving environment and subsequently affect the degree of care. However, some researchers reported that higher economic status is a sufficient prediction of higher and not lower care giving burden (Caro et al., 1984). They maintain that middle class adult children tend to provide more financial aid (money, gift, loans) while working class adult children provide more services, they also suggested that this is partially influenced by the fact that lower class adult children tend to live closer to their elderly parents.

Rosser and Harris (1965) argued that kinship is an evolving process with roles and relationship changing as the family passes through its cycle of development. They indicated that the nature and extent and direction of assistance given by adult children to elderly parents will alter overtime as the domestic and personal circumstances of parents and children shift and change. They also pointed out that as children approach old age dependency on children increases. Cicirelli (1981) reported that there is a pattern of mutual dependency between adult children and elderly parents depending on the stage of the family life cycle. In some cases at higher social economic levels, elderly parents, she maintains, continue to provide help to adult children when parents now attained advanced age, as they go into infirmity with loss of rigour, possible disability, loss of income after retirement or a combination of factor, the balance shift and adult children provide greater amount of care to elderly parents. 


\section{Methodology}

The descriptive cross-sectional study was carried out in University of Calabar, Calabar, Cross River State, Nigeria. The University of Calabar was selected as the study area for the researcher's convenience which permitted close monitoring and because the population of workers is cosmopolitan and represents a way of life for millions of adult Nigerians from the 36 states and the federal capital territory working within and outside their states of origin. Purposive sampling was adopted to select 350 adult children (male and female) workers in the University of Calabar aged 29-71years with at least one living parent. Respondents represent both academic and non-academic staff of the institution selected from Faculties of Arts and Humanities, Natural and Applied Science, and Agriculture. Others units included were the Institute of Education, College of Medicine, Central Administration Departments and Graduate School.

A questionnaire elicited information on the socio-economic conditions of the adult children, number of children in the household, number of children in each level of education, and the form of help provided by adult children to elderly parents. Help provided by adult children was conceptualized and measured on a six-item scale adopted from Cicirelli's 16-item scale (Cicirelli, 1989). The six items chosen were judged to be relevant to Nigeria's elderly. The dependent variable which is care of the elderly was operationalized as adult children's provision of services to elderly parents in the six service areas namely (1) Help with Financial Resources for maintenance (2) Personal Care (3) Housing Provision (4) Security and Protection (5) Provision of Health Care Services and (6) Emotional Support.

The independent variables are adult children net income and family size and stage in family life cycle of the adult children. Adult children's net income was taken as the income reported by the respondents. Family size was operationalized as the total number of children in the household consisting of the number of children still living in the house and those who are outside but still dependent on the respondent for some form of support. Stage in family life cycle was operationalized as the distribution of children in each education level (nursery, primary, secondary and higher institution) according to age range of adult children.

All analysis was done manually at 5 per cent level of significance. The socio-demographic characteristics of the respondents were presented in frequency distribution tables. Relationship between family size, income of adult children and adult children care of elderly parents were assessed using chi square test, while descriptive analysis was used to assess the stage in family life cycle operationalizes as the distribution of children at various levels of schooling according to age ranges of adult children 


\section{Results}

Table 1 shows the socio-economic characteristics of adult children. The majority $(53.43 \%)$ of the respondents are females; the age of adult children ranges from 29 to 71 years ( \pm 8.7 years). The age of respondents span over 65 years because some of them were retired Professors on contract. A higher proportion $(40.29 \%)$ of respondents was in the age range of 29-38 years of age. Over 71 per cent of respondents were married.

Table 1: Socio-economic characteristics of adult children

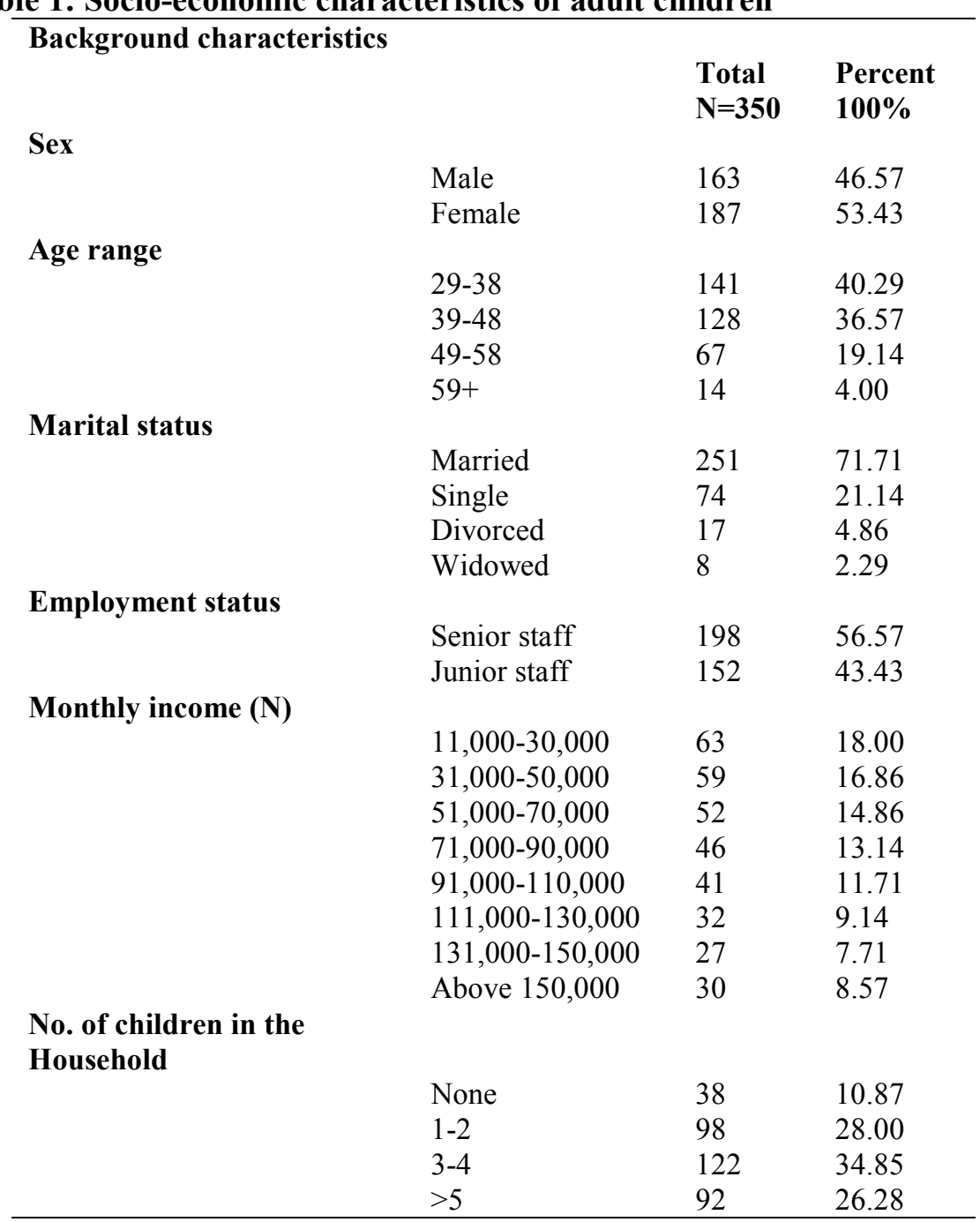

As it relates to monthly income, 18 per cent of adult children received between $\mathrm{N} 11,000$ and $\mathrm{N} 30,000$, while barely 10 per cent received over $\mathrm{N} 150,000$ per month. The salary (net pay) is as low as N11,000 because some of the respondents are junior contract staff. As regards number of children in 
the household which, in the context of this study, is defined as the sum total of the number of children still living in the house and the number of children outside the house but still dependent on the adult children for some form of support. Approximately 11 per cent of adult children had no child within their household and 34.9 per cent had between 3-4 children.

Table 2 shows the distribution of children in the household. This includes number of children still living in the house and those who are outside but still dependent on the respondent for some form of support. The reduction in sample size from 350 to 312 is accounted for by specific population targeted nature of the questions. Only adult children with at least a child in the household were eligible. Of the 1,080 children, 580 children were living in home while 500 were outside but still dependent on the adult children for support. The highest proportion (37.96\%) of children is found in the household of respondents aged 39-48 years and begins to show decline from 49-58 years.

Table 2: Distribution of children in the household according to Age of adult children

\begin{tabular}{|l|c|c|c|c|l|}
\hline & & $\begin{array}{c}\text { No. of children } \\
\text { No. of } \\
\text { children at } \\
\text { home }\end{array}$ & $\begin{array}{c}\text { living outside } \\
\text { the home but } \\
\text { still dependent } \\
\text { on adult } \\
\text { children }\end{array}$ & $\begin{array}{c}\text { Total no. } \\
\text { of children } \\
\text { in } \\
\text { household }\end{array}$ & Percentage \\
\hline $29-38$ & 115 & 287 & 85 & 372 & 34.44 \\
\hline $39-48$ & 121 & 187 & 223 & 410 & 37.96 \\
\hline $49-58$ & 65 & 82 & 168 & 250 & 23.15 \\
\hline $59+$ & 11 & 24 & 24 & 48 & 4.44 \\
\hline Total & 312 & 580 & 500 & 1080 & 100 \\
\hline
\end{tabular}

Table 3 shows the family size by age of respondents. Adult children within the age range of 29-38 years had the least number of children (1-2) within the household. Household with about 3-4 children is more peculiar to adult children aged 39-48 years and those aged 59 years and above.

Table 3: Number of children in respondents' household by age of Adult children

\begin{tabular}{|l|c|c|c|}
\hline & \multicolumn{3}{|c|}{ Number of children in household } \\
\hline Age of adult children & $\mathbf{1 - 2}$ & $\mathbf{3 - 4}$ & $\mathbf{2 ~ 5}$ \\
\hline $29-38$ & 47.19 & 34.72 & 18.09 \\
\hline $39-48$ & 21.79 & 44.69 & 33.52 \\
\hline $49-58$ & 31.42 & 37.12 & 31.43 \\
\hline $59+$ & 28.57 & 42.86 & 28.57 \\
\hline
\end{tabular}


Table 4 shows the cross tabulation between family size and care of the elderly. Family size was defined as number of children in adult children household, indicated by the number of children living at home and those living outside but still dependent on the adult children for some form of support. Adult children in household having between 1-2 children provided more of emotional care $(19.33 \%)$ and the least form of care was provided in the area of housing (13\%). Adult children in household with 5 or more children provided most care in the area of health (18.59\%). The adult child's family size is significantly related to adult child's provision of care to elderly parents. The calculated chi-square value is greater than the table value, i.e. $17.122>12.6$, the null hypothesis was therefore rejected and alternate hypothesis accepted at 5\% significance level.

Table 4: Adult children income and provision of services to elderly parents response in percentages

\begin{tabular}{lllllll}
\hline $\begin{array}{l}\text { Family } \\
\text { size }\end{array}$ & $\begin{array}{l}\text { Financial } \\
\text { help }\end{array}$ & $\begin{array}{l}\text { Help with } \\
\text { personal } \\
\text { care }\end{array}$ & Housing & Security & $\begin{array}{l}\text { Health } \\
\text { care }\end{array}$ & $\begin{array}{l}\text { Emotiona } \\
\text { 1 support }\end{array}$ \\
\hline $1-2$ & 17.00 & 13.69 & 13.00 & 15.74 & 17.33 & 19.33 \\
\hline $3-4$ & 16.00 & 17.33 & 13.67 & 14.77 & 14.65 & 18.47 \\
\hline$\geq 5$ & 15.85 & 13.76 & 17.88 & 11.53 & 18.59 & 15.06 \\
\hline
\end{tabular}

Figure 1 shows the stage in family life cycle of respondent represented by percentage of children in each level of education by adult children age group. The adult children within the 29-38 age bracket had 50 per cent, 60 per cent, 50 per cent and 25 per cent of their children in the nursery, primary, secondary and higher level of education of education respectively. Within the age range of 39-48 years, the analysis shows a shift in the percentage of children in the various levels of education with 35 per cent, 39 per cent, 65 per cent and 55 per cent of the children in nursery, primary level, secondary and higher level of education of education respectively. This age range indicate the stage where the adult children have greater burden of raising their across all levels of education. 


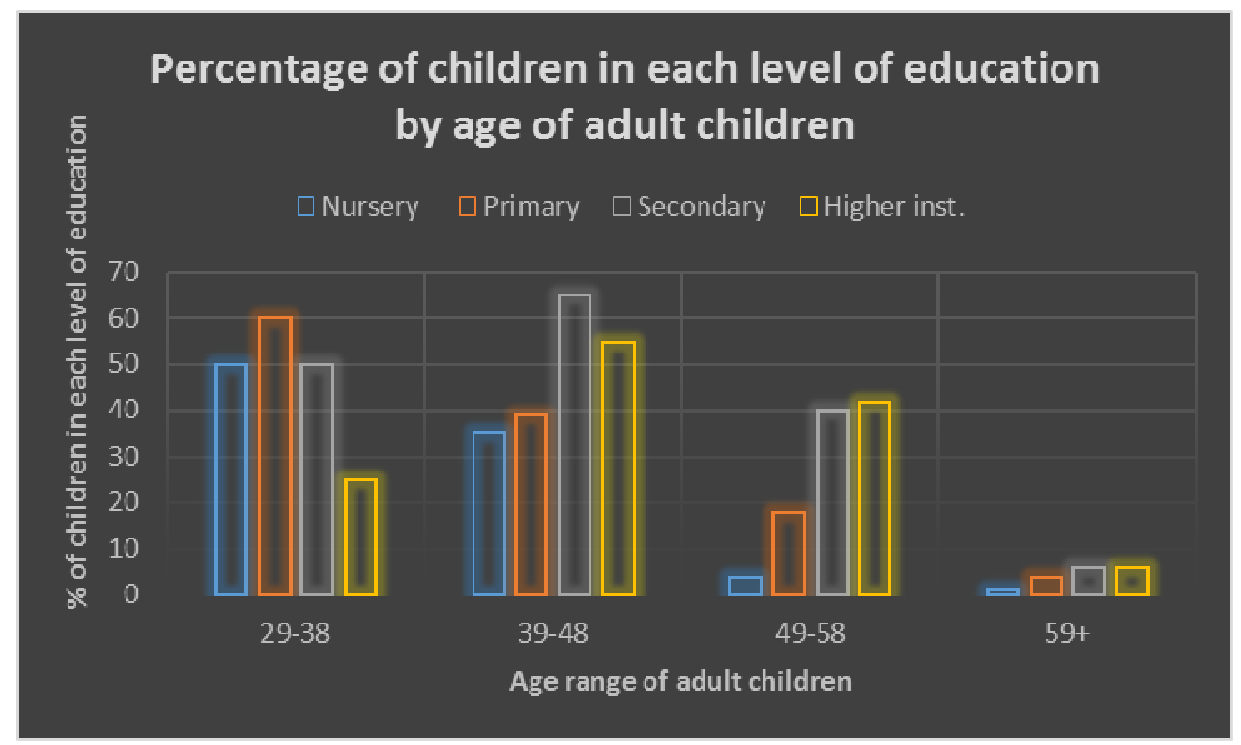

Figure 1: Percentage of children in each level of education by age of adult children

Among those aged 49-58, less than 5 per cent of the respondents' children were in nursery school, 18 per cent in primary, and 40 per cent in secondary school while 42 per cent were reported to be studying in higher institutions. Lastly, there was a major reduction in the number of children at the different levels of education for adult children over 59 years of age. Only 1 per cent and 4 per cent of respondent's children were in nursery and primary schools and 6 per cent in both secondary and higher institution. The distribution of children in school for this age group suggests that the adult children have finished raising their children across all levels of education.

Table 5 shows the cross-tabulation of adult children income and provision of services to elderly parents in six service areas. Financial help (28.63\%) was the most reported form of care to the elderly parents by adult children earning between N131,000 - N150,000. Respondents earning above N150,000 monthly reported providing more of emotional care to elderly parents compared to other forms of care. Although the variation in monthly income levels of the adult children did not affect caregiving to their parents, there was no significant relationship between the income of adult children and care of elderly parents. The calculated chi-square value is less than the table value $(12.305<55.8)$, the null hypothesis was therefore accepted. 
The Nigerian Journal of Sociology and Anthropology Vol. 12 no. 1

Table 5: Adult children income and provision of services to elderly parents response in percentages

\begin{tabular}{lllllll}
\hline Income level (N) & $\begin{array}{l}\text { Financial } \\
\text { help }\end{array}$ & $\begin{array}{l}\text { Help with } \\
\text { personal } \\
\text { care }\end{array}$ & Housing & Security & $\begin{array}{l}\text { Health } \\
\text { care }\end{array}$ & $\begin{array}{l}\text { Emotional } \\
\text { support }\end{array}$ \\
\hline $11,000-30,000$ & 15.79 & 17.44 & 14.77 & 17.18 & 14.72 & 20.1 \\
\hline $31,000-50,000$ & 17.95 & 17.06 & 14.04 & 17.9 & 14.65 & 18.4 \\
\hline $51,000-70,000$ & 17.55 & 17.28 & 13.88 & 19.33 & 14.06 & 17.9 \\
\hline $71,000-90,000$ & 16.55 & 18.35 & 13.54 & 18.82 & 14.39 & 18.35 \\
\hline $91,000-110,000$ & 15.2 & 15.62 & 15.2 & 18.52 & 16.21 & 19.25 \\
\hline $110,000-130,000$ & 16.42 & 18.11 & 11.37 & 17.68 & 15.58 & 20.84 \\
\hline $131,000-150,000$ & 28.63 & 13.68 & 11.54 & 16.67 & 11.96 & 17.52 \\
\hline$>150,000$ & 15.95 & 18.54 & 11.8 & 17.6 & 14.23 & 21.91 \\
\hline
\end{tabular}

\section{Discussion}

This study reports the result of a community-based study of the effect of noncultural factors of adult children income, family size and stage in family life cycle on adult children provision of care to elderly parents among adult children in University of Calabar, Cross-River, Nigeria. The mean age of the respondents was 42 years and about 53.43 per cent were females.

The dependent variable was care of the elderly defined as adult child provision of services to elderly parents in six identified service areas adopted from Cicirelli's 16 service areas (Cicirelli, 1981). The areas of service were (i) provision of financial resources for maintenance (ii) help with personal care (iii) provision of housing (iv) security and protection (v) provision of health services and medication (vi) provision of emotional support.

As a basis for investigating some non-cultural factor that influence adult child's provision of care to elderly parents, the following hypotheses were formulated; the adult children provision of care to elderly parent is not significantly related to adult children income; family size is not a strong factor for the provision of care to the elderly; family size and stage in family life cycle is not a strong factor for the provision of care to the elderly.

Results suggest that income of adult children as a single variable has no direct bearing on the amount of help adult children provide to elderly parents. But within the context of the theoretical framework for this study, the independent variables of family size and stage in family life cycle which considers the situational exigencies of the adult child, viz. number of children in the household and their distribution in the different level of schooling, have a bearing on the income of the adult child.

The finding is in consistence with the report of Harris (1975), Sussman (1965) and Streib (1979), who reported that a large majority of the aged neither expect nor actually receive regular monetary aid from their children. Streib 
(1979) found that only 7 per cent of the elderly in their study received regular financial help from their children and they all confirmed in their report, that most giving despite the income level of the children is limited to emergency help and gifts at special occasions.

The significant relationship established between the adult children's family (household) size and the care of the elderly corroborates the report of Pearlin et al. (1990). They reported that socioeconomic characteristics of the caregiver are likely to specify the caregiving environment and subsequently affect the degree of care.

Adult children within the age range of 29-38 years have been found to be at the early stages of raising their children who are predominantly in the nursery, primary school with less proportion in the secondary school. More children in nursery and primary school will suggest a period when adult children are in their early family stages and elderly parents are likely to be middle aged.

This study further reveals that the adult children within the age range 39-48 and 49-58 have the majority of the children outside the household in higher institution most of who are still dependent on them for financial support. Respondent aged 59 years and above had very few children in the household who are dependent on the parents. The finding supports the studies by Troll (1971) and Shanas (1979), who reported that the period of time when parents are in their middle age and children are in their early family stage is likely to be the time two generation are most geographically distance with greater care burden for new children and therefore less care of the elderly parents. Rosser and Harris (1965) also support this finding by their report that kinship is an evolving process with roles and relationship changing as the family passes through its cycle of development. This is explained succinctly by the findings of this study that the nature and extent and direction of assistance given by adult children to elderly parents alter over time as the domestic and personal circumstances of parents and children shift and change.

\section{Conclusion}

The study suggests that while adult children may want to provide care for elderly parents in the six service areas examined, family size as measured by the number of children in the household and stage in family life cycle as measured by the distribution of respondents' children in the different level of schooling, have a bearing on the income of the adult child. The inclusion of the elderly in poverty alleviating programmes may therefore be a great option to be considered by the government so as to reduce the strain on the income of adult children which affects the care provided to elderly parents and further improve the quality of life of the elderly. 


\section{References}

Abdulrahman, P.A. 1988. The Sociology of the Aging Process. A Paper Presented at the Conference on the Aged in Sokoto State.

Apt, N.A. 1993. The Storm Clouds are Grey. In Tout, K. (ed.). Elderly Care: A world Perspective. New York: Chapman and Hall. 10-12.

Cicirelli, V.G. 1983. A comparison of helping behavior to Elderly parents of adult Children with intact and disrupted marriages. The Gerontologist. 23: 619-625.

Cicirelli, V.G. 1988. A measure of filial anxiety regarding anticipated care of elderly parents. The Gerontologist. 23: 478-482.

Cicirelli, V.G. 1990. Family support in relation to health problems of the elderly. In T.H. Brubaker (ed.). Family relationship in later life. Newbury Park, CA: Sage. 212-228.

Finch, J. 1989. Family Obligation and Social Change. Cambridge, Polity.

González-González, C.; Sánchez-García, S.; Juárez-Cedillo, T.; RosasCarrasco1, O.; Gutiérrez-Robledo, L.M. and García-Peña, C. 2011. Health care utilization in the elderly Mexican population: Expenditures and determinants. BMC Public Health. 11: 192.

Harris, L. 1975. The Myth and Reality of Ageing in America. Washington D.C.: National Council on Ageing.

National Population Commission. 2013. UNCP\&D Report on status of implementation of ICPD program of action.

Pearlin, L.I.; Mullan, J.J.; Semple, S.J. \& Skaff, M. 1990. Care Giving and the Stress Process. An overview of concepts and measure. The Gerontologist. 30: 583-594.

Rosenmayar, L. 1993. The family undisturbed: generational realities in traditional Africa. In Toute, K. (eds.). Elderly care: A world perspective. New York: Chapman and Hall. 15-21.

Rosser, C. \& Harris, C.C. 1965. The Family and Social change. London: Routledge.

Shanas, E. 1979. Social Myth as Hypothesis: The Case of the family Relation of Older people. The Gerontologists. 19: 3-9.

Strieb, G.F. 1979. Older Families and their Trouble: Families and Social Responses. In Lasswell, M.E. \& Lasswell, T.E. (eds.). Love, Marriage, Family. A Developmental Approach. 5310540 Glenview, IL: Scott. Foresman.

Sussman, M.B. 1965. Relationship of Adult Children and their Parents in the United States. In Shanas, E. and Streib, G.F. (eds.). Social Structure and the family. Englewood Cliffs, N.J: Prentice Hall.

Troll, L.E. 1971. The family of later life: A decade review. Journal of Marriage and the Family. 33: 263-290.

UNDESA. 2007. State of older people in Africa. Regional review \& appraisal of the Madrid International Plan of Action on Ageing.

UNFPA/Help Age International. 2012. Ageing in the twenty-first century: a celebration and a challenge. 168. 
Wenger, G.C. 1984. The supportive network: coping with old age. London: George, Allen and Unwin. 